\title{
Plutonium Immobilization Can Loading Conceptual Design
}

by

E. Kriikku

Westinghouse Savannah River Company

Savannah River Site

Aiken, South Carolina 29808

C. Ward

M. Stokes

B. Randal

J. Steed

R. Jones

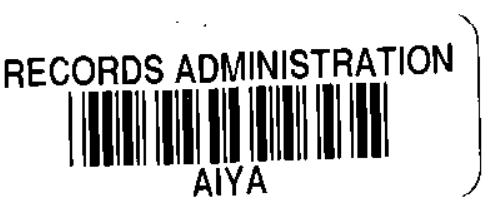

L. Hamilton

L. Rogers

J. Fiscus

G. Dyches

This paper was prepared in connection with work done under the above contract number with the U. S. Department of Energy. By acceptance of this paper, the publisher and/or recipient acknowledges the U.S. Government's right to retain a nonexclusive, royalty-free license in and to any copyright covering this paper, along with the right to reproduce and to authorize others to reproduce all or part of the copyrighted paper. 


\section{DISCLAIMER}

This report was prepared as an account of work sponsored by an agency of the United States Government. Neither the United States Government nor any agency thereof, nor any of their employees, makes any warranty, express or implied, or assumes any legal liability or responsibility for the accuracy, completeness, or usefulness of any information, apparatus, product, or process disclosed, or represents that its use would not infringe privately owned rights. Reference herein to any specific commercial product, process, or service by trade name, trademark, manufacturer, or otherwise does not necessarily constitute or imply its endorsement, recommendation, or favoring by the United States Government or any agency thereof. The views and opinions of authors expressed herein do not necessarily state or reflect those of the United States Government or any agency thereof.

This report has been reproduced directly from the best available copy.

Available to DOE and DOE contractors from the Office of Scientific and Technical Information, P. O. Box 62, Oak Ridge, TN 37831; prices available from (423) 576-8401.

Available to the public from the National Technical Information Service, U. S. Department of Commerce, 5285 Port Royal Road, Springfield, VA 22161. 
WSRC-TR-98-00229

\section{Plutonium Immobilization Can Loading Conceptual Design (U)}

July 1, 1998

Westinghouse Savannah River Company Savannah River Site

Aiken, SC 29808 


\title{
Plutonium Immobilization \\ Can Loading Conceptual Design (U)
}

The following Plutonium Immobilization Can Loading Team members contributed to this report.

\author{
Bill Randall \\ NMS\&S \\ Jim Steed \\ NMS\&S \\ Robert Jones \\ NMS\&S \\ Clyde Ward \\ SRTC/EES \\ Mitchell Stokes \\ SRTC/EES \\ Lane Rogers \\ SRTC/EES \\ Greg Dyches \\ SRTC/EES \\ James Fiscus \\ SRTC/EES \\ Lee Hamilton \\ SRTC/EES \\ Michael Restivo \\ SRTC/EES \\ Eric Kriikku \\ SRTC/EES
}




\section{Table of Contents}

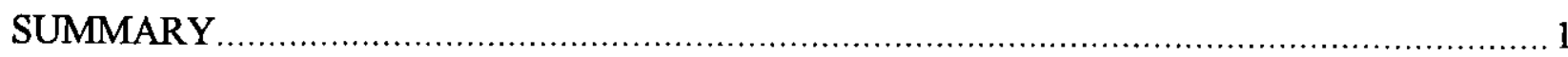

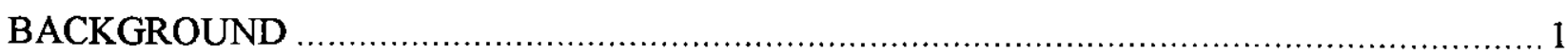

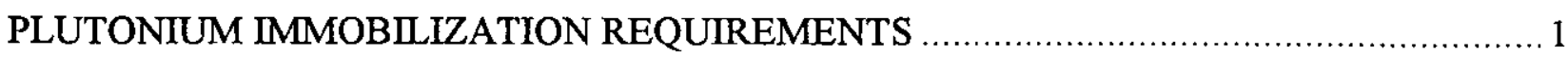

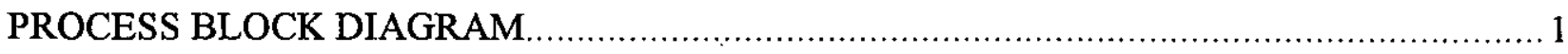

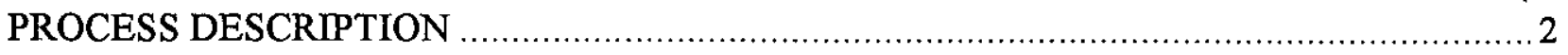

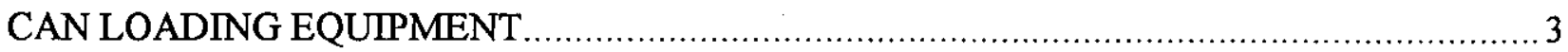

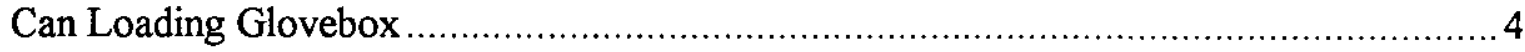

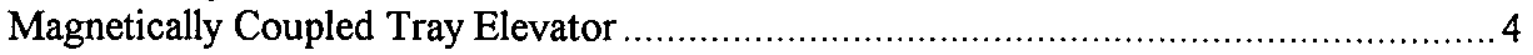

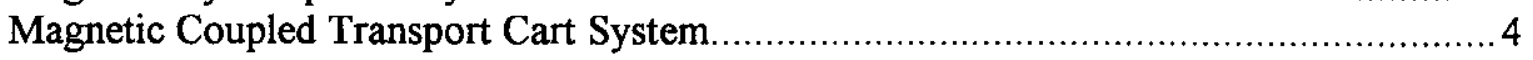

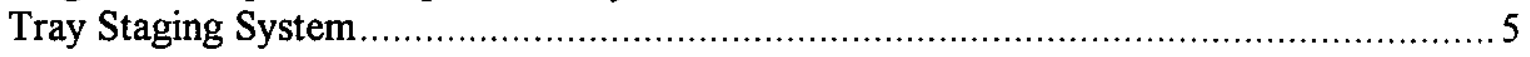

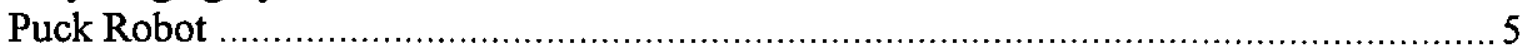

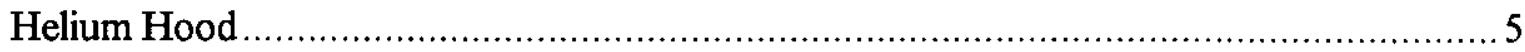

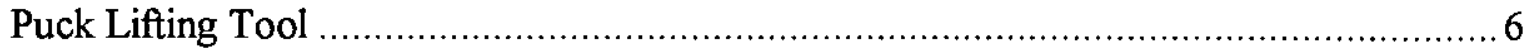

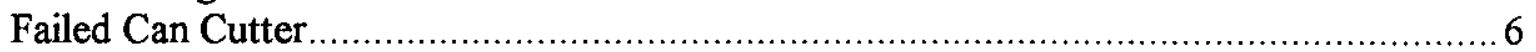

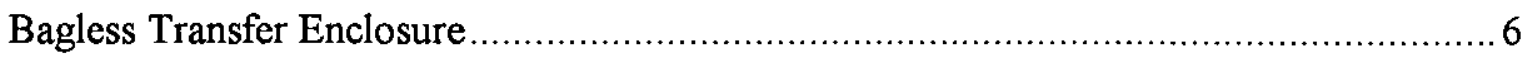

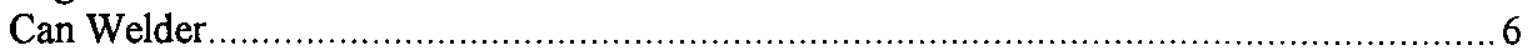

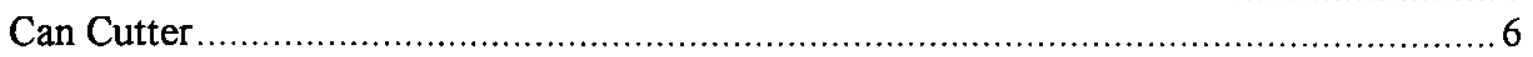

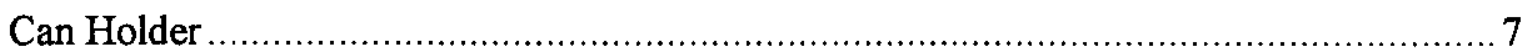

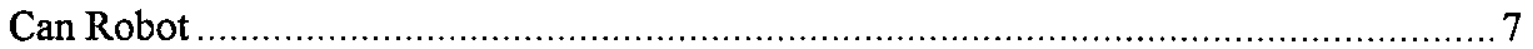

Helium Leak Detector Chamber ..................................................................... 7

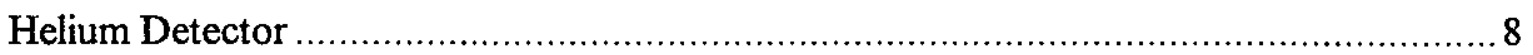

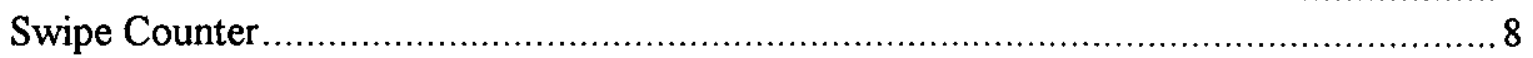

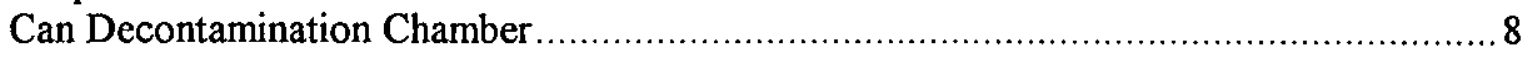

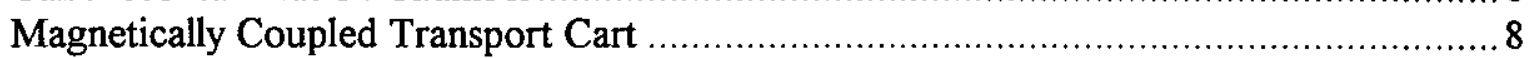

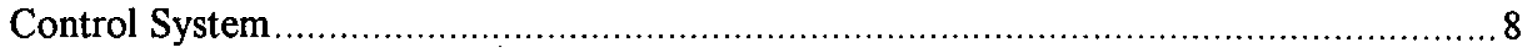

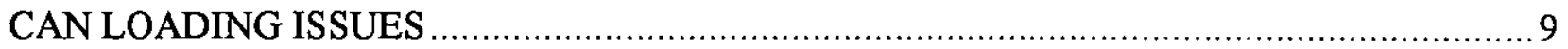

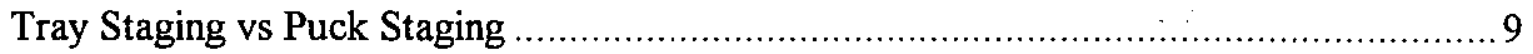

Helium Hood vs Helium Atmosphere ............................................................... 9

Can Robot vs Hard Automation .................................................................. 10

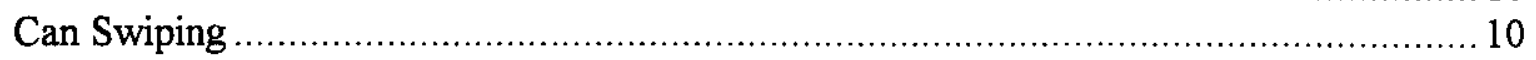

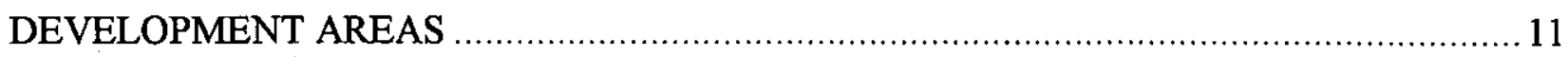

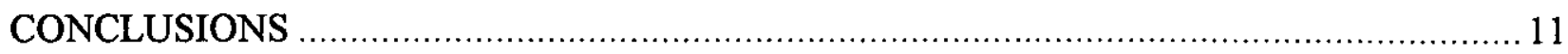

Attachment 1 - Can Loading Process Block Diagram.................................................... 12

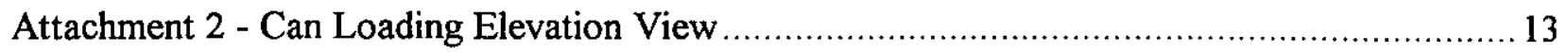

Attachment 3 - Can Loading Plan View AA, Can loading Glovebox ................................... 14

Attachment 4 - Can Loading Plan View BB, Bagless Transfer Enclosure ............................... 15 


\section{SUMMARY}

The Plutonium Immobilization Facility will encapsulate plutonium in ceramic pucks and seal the pucks inside welded cans. Remote equipment will place these cans in magazines and the magazines in a Defense Waste Processing Facility (DWPF) canister. The DWPF will fill the canister with glass for permanent storage. This report discusses the Plutonium Immobilization can loading conceptual design and includes a process block diagram, process description, preliminary equipment specifications, and several can loading issues. This report identifies loading pucks into cans and backfilling cans with helium as the top priority can loading development arcas.

\section{BACKGROUND}

The Plutonium Immobilization Facility design will minimize operator exposure and prevent the spread of contamination. To accomplish these goals, a system must package contaminated materials in clean containers and not release contamination. Traditional methods of removing plutonium from process gloveboxes in preparation for packaging involves the use of manual bagout procedures utilizing plastic bags. This method is not acceptable in the Plutonium Immobilization Facility. Engineers at the Savannah River Site (SRS) developed a system for removing plutonium from a glovebox directly into an all metal, welded, leaktight container, free of external contamination. The process, known as bagless transfer, utilizes a Tungsten-Inert-Gas (TIG) welding process to seal plutonium in a can. The process then separates the transfer can from the glovebox environment while maintaining glovebox and can integrity. A semi-automated bagless transfer unit is in operation at the Savannah River Site FB-Line Plutonium Facility. The Plutonium Immobilization Can Loading operations will use this system as a baseline.

\section{PLUTONIUM IMMOBILIZATION REQUIREMENTS}

The Plutonium Immobilization facility must produce approximately 560 pucks per day to meet production requirements. The can loading system must be able to automatically load at least 24 pucks per hour into puck cans. Remote equipment will load the puck cans into magazines and load the magazines into racks inside the DWPF canisters. The DWPF fills canisters with approximately 91 inches of glass and the glass must surround the puck cans, magazines, and racks.

Normal can loading system operations will be performed remotely, but maintenance and repairs will be performed manually. The can loading system design shall minimize the amount of equipment in the containment, minimize the complexity of the equipment in the containment, design the equipment for minimal maintenance, and design the equipment for glovebox repair and replacement.

\section{PROCESS BLOCK DIAGRAM}

Attachment 1 is the can loading process block diagram and it shows the detailed can loading process steps. The process block diagram is based on the can loading steps contained in the Plutonium Immobilization Plant, First Stage Immobilization, Process Flow Drawing (P-6, Rev. A, 4/6/98). 


\section{PROCESS DESCRIPTION}

Attachment 2 shows the can loading concept elevation view, Attachment 3 shows the can loading glovebox plan view, and Attachment 4 shows the bagless transfer enclosure plan view. The following paragraphs describe the can loading process.

A tray of pucks enters the can loading glovebox on a magnetically coupled transport cart and the tray staging system lifts the tray from the cart. The puck robot (Cartesian type) uses a vacuum cup on a 40 inch pipe to remove the pucks from the tray and load them in the puck can. The cart moves the empty tray from the tray staging system to the elevator. The puck robot can remove pucks from trays at either lift station and the cart can move one tray under a second tray at a lift station. This will allow the system to load pucks while the cart removes an empty tray and brings a new tray to the tray staging system.

The puck robot places the helium hood over the can plug. The helium hood then grabs the can plug using a vacuum cup. The puck robot places the helium hood over the puck can and the helium hood seals to the can. The helium hood removes the air from the can, fills the can with helium, and inserts the plug into the can. The bagless transfer system welds the plug to the can wall, and cuts the can and plug leaving the can stub in the sphincter seal.

The bagless transfer can holder lowers the can and the can robot swipes approximately $80 \%$ of the can exterior. The can robot loads the swipe in a swipe counter and seals the counter. After the counting is complete, the can robot removes the can from the bagless transfer can holder, places it in the helium bell jar leak detector to ensure the weld is leak tight, and seals the detector. After the leak test is complete, the can robot places the can in a rack on the magnetically coupled transport cart and the can leaves the bagless transfer enclosure.

New swipes and new cans, manually pre-loaded with plugs, are placed in a rack external to the bagless transfer enclosure. The magnetically coupled transport cart brings the rack of cans and swipes to the bagless transfer enclosure. The can robot removes the cans and swipes from the rack and places them in storage areas. The can robot places used swipes on the rack and the magnetically coupled transport cart will remove the swipes from bagless transfer enclosure. The can robot moves a new can from storage into the bagless transfer can holder and then the bagless transfer system raises the can. The previous can stub is pushed by the new can into the can loading glovebox and the puck robot places the stub on an empty tray. The empty tray and can stub leave the loading glovebox on the magnetic coupled transport cart. The stub is taken to the elevator and then to the waste handling glovebox. The puck robot removes the plug from the new can and the loading process resumes.

Operators will use cameras and welder feedback to determine can weld failures. The bagless transfer machine will push cans that experience weld failures up into the sphincter seal exposing the top 3 inches of the can above the sphincter seal. The puck robot will place the can cutter over the exposed can and the can cutter will cut the can open near the top. This cut will be in the void space above the pucks. The puck robot will remove the can cutter, the can top, and the pucks from the damaged can. The bagless transfer can holder will push the empty failed can up into the sphincter seal. The can robot will place an empty can in the bagless transfer can holder and the can holder will use the empty can to push the failed can into the can loading glovebox. The transfer carts will remove all pucks and cut can pieces from the can loading glovebox and all 
loaded cans from the bagless transfer enclosure. The cut can pieces and any can stubs will be sent to the waste handling glovebox. These items will have sharp edges and will require special handling procedures if they are manually processed. Operators will manually perform any system maintenance including sphincter seal replacement.

The can robot will place cans that fail the swipe test in a decontamination chamber. After completing the decontamination process, the can robot will swipe the can again. If the can passes the swipe test, the can robot will place the can in the leak test chamber and process the can as described above. If the can fails the second swipe test, the can robot will place it in the bagless transfer can holder. The bagless transfer can holder will push the failed can up into the sphincter seal and this will push the stub into the can loading glovebox. The puck robot will place the stub on an empty tray and the can robot will load a new can into the bagless transfer can holder. The bagless transfer can holder will push the failed can into the sphincter seal exposing the top 3 inches of the can above the sphincter seal. The puck robot will process these reject cans in a similar manner as the weld failure cans described above.

The can robot will place cans that fail the leak check in the bagless transfer can holder. The bagless transfer can holder will push the failed can up into the sphincter seal and this will push the stub into the can loading glovebox. The puck robot will place the stub on an empty tray and the can robot will load a new can into the bagless transfer can holder. The bagless transfer can holder will push the failed can into the sphincter seal exposing the top 3 inches of the can above the sphincter seal. The puck robot will process these reject cans in a similar manner as the weld failure cans described above.

\section{CAN LOADING EQUIPMENT}

Table 1 shows the Can Loading equipment list and potential vendors for each equipment item. The following paragraphs describe the preliminary specifications for each.

Table 1 - Can Loading Equipment

$\underline{\text { Item }}$

Can Loading Glovebox

Magnetically Coupled Tray Elevator

Magnetically Coupled Transport Cart

Tray Staging System

Puck Robot

Helium Hood

Puck Lifting Tool

Can Cutter

Bagless Transfer Enclosure

Can Welder

Can Cutter

Can Holder

Can Robot

Helium Leak Detector Chamber
Potential Vendor

Walker Stainless Equipment Co.

Custom EES Design

Custom EES Design

Custom EES Design

Motionex, Inc.

Custom EES Design

Custom EES Design

Tri-Tool Inc.

Walker Stainless Equipment Co. Arc Machines Inc.

Tri-Tool Inc.

Custom EES Design

Reis Robotics

Custom EES Design 
Table 1 - Can Loading Equipment (cont.)

Item

Helium Detector (Mass Spectrometer)

Swipe Counter

Can Decontamination Chamber

Magnetic Coupled Transport Cart

Control System
Potential Vendor

Varian Associates

Canberra Industries

Custom EES Design

Custom EES Design

Modified Commercial

\section{Can Loading Glovebox}

The can loading glovebox shown in Attachment 2 will allow.pucks to enter on transport trays through an airlock, contain the equipment to load pucks into cans, and support the bagless transfer sphincter seal. The glovebox will be approximately 60 inches long, 48 inches wide, and 60 inches high. The glovebox requires several gloveports, removable panels, and extensive shielding. The glovebox will be fabricated from 304 stainless steel, lead, and water extended polyester (WEP). The glovebox will be designed to hold a slight negative pressure, approximately 0.5 inches of water, and conform to appropriate American Glovebox Society (AGS-1994-G001, Guidelines for Gloveboxes) and SRS glovebox standards.

\section{Magnetically Coupled Tray Elevator}

The magnetically coupled tray elevator will raise and lower transport trays from the transport cart to the overhead tray transport system. Transport tray concepts hold up to 16 one pound pucks. The tray will weigh approximately 10 pounds, so the tray elevator must be able to lift a 26 pound payload. The elevator size will be driven by the transport tray size. The transport tray is approximately 12 inches by 12 inches, so the elevator shaft will be about 16 inches by 20 inches. These dimensions provide space for the elevator acme screw and guide rails. The tray elevator parts will be fabricated from 304 stainless steel where ever possible and all moving parts will be covered when possible. The magnetically coupled elevator design will allow the drive motor to be outside the containment for easier maintenance and cleaning.

\section{Magnetic Coupled Transport Cart System}

The magnetic coupled transport cart system will move puck transport trays from the tray elevator to the tray staging system. Transport tray concepts hold up to 16 one pound pucks and the tray will weigh approximately 10 pounds, so the transport cart must be able to handle a 26 pound payload. The transport cart size will be driven by the transport tray size. The transport tray is approximately 12 inches by 12 inches, so the transport cart will be about 8 inches by 8 inches. The transport cart parts will be fabricated from 304 stainless steel where ever possible. The magnetically coupled cart design will allow the drive system and other components to be outside the containment for easy maintenance and cleaning. The cart and cart rails will be the only system parts inside the glovebox. 


\section{Tray Staging System}

The tray staging system will be two tray lift stations. Each station will lift a puck transport tray from the transport cart to stage the tray. The puck robot can access pucks on either tray and the cart can move one tray under a second tray at a lift station. Transport tray concepts hold up to 16 one pound pucks and the tray will weigh approximately 10 pounds, so the tray staging lift units must be able to lift a 26 pound payload. The tray lift station size will be driven by the transport tray size. The transport tray is approximately 12 inches by 12 inches, so the tray lift stations will be about 12 inches long by 18 inches wide by 10 inches tall. The lift height will provide sufficient clearance for the cart carrying a tray to move under a lifted tray. The tray staging system parts will be fabricated from 304 stainless steel where ever possible and all moving parts will be covered when possible. The magnetically coupled lift stations design will allow the drive motors to be outside the containment for easier maintenance and cleaning.

\section{Puck Robot}

The puck robot, Cartesian type, will use a puck lifting tool to lift pucks from the transport trays and place them in the puck can. The puck robot will also handle can stubs, reject cans, can cutter, and the helium hood. The puck robot's maximum payload will be the 30 pound can cutter. The puck robot requires three degrees of freedom, $\mathrm{X}-\mathrm{Y}-\mathrm{Z}$, and a gripper. The $\mathrm{X}$ axis will provide 52 inches of travel, the $Y$ axis will provide 40 inches of travel, and the $Z$ axis (up and down) will provide 44 inches of travel. These travel limits will allow the puck robot to fit inside the 60 inch long by 48 inch wide by 60 inch tall can loading glovebox. Each axis requires a repeatability of $+/-0.025$ inches and a velocity range from 0 to 10 inches/second.

The gripper will lift the following items; the puck lifting tool, can cutter, helium hood, puck cans, and can stubs. Each item has a 3 inch outer diameter or will have a 3 inch outer diameter lifting point, so the gripper will always grab the same shape. The puck robot and gripper parts will be fabricated from 304 stainless steel where ever possible and all moving parts will be covered when possible. If possible, the internal cavities will be slightly pressurized to help prevent contamination from entering the robot and gripper.

\section{Helium Hood}

The helium hood will fill the puck can with helium and insert the can plug. The helium hood will perform the following operational steps. First, the hood will grab the can plug with a vacuum cup. Second, the puck robot will place the hood on the puck can. Third, the helium hood will seal to the puck can and pull a vacuum on the puck can. Fourth, the hood will insert helium into the can. Fifth, the hood will place the can plug into the can. The FB-Line bagless transfer system pulls a vacuum to 20 inches of mercury on the product can, backfills with +3 psi of helium, pulls the vacuum a second time, and backfills with helium again to ensure helium is in the product can. The can loading helium hood will be able to duplicate this. The helium hood requires position feedback ( $+/-0.05$ inches) and force control on the can plug insertion actuator to ensure the plug is inserted to the proper position. The hood requires an umbilical cord to supply the vacuum lines, helium lines, and plug insertion actuator power and position feedback cables. The helium hood parts will be fabricated from 304 stainless steel where ever possible. 


\section{Puck Lifting Tool}

The puck lifting tool will be used by the puck robot to pick up pucks and place them inside the puck can. The lifting tool will carry one puck at a time, so the maximum payload will be approximately one pound. The lifting tool will be a hollow pipe approximately 44 inches long and the lower 30 inches must be less than 2.25 inches in diameter. The lifting tool lower 30 inches must fit inside the 2.88 inch inner diameter by 30 inch long puck can. The lifting tool will have a vacuum cup on the lower end and a 3 inch diameter grab point on the top end. The 3 inch diameter section will allow the robot gripper to firmly hold the tool. This grab point will be the top 4 inches of the tool and will never enter the puck can. The puck lifting tool will be fabricated from 304 stainless steel. The lifting tool requires an umbilical cord to provide the vacuum line for the vacuum cup.

\section{Failed Can Cutter}

The failed can cutter will cut open cans that fail in the welder or fail the leak check. Failed cans will be pushed up into the sphincter seal exposing the top 3 inches of the can above the seal and the puck robot will place the failed can cutter over the exposed can. The failed can cutter will be a commercially available pipe cutter sized to cut 3 inch outer diameter thin walled pipe. The can cutter parts will be fabricated from 304 stainless steel where ever possible and all moving parts will be covered when possible. The can cutter will require an umbilical cord to provide power to the can cutter.

\section{Bagless Transfer Enclosure}

The bagless transfer enclosure will contain the bagless transfer system, the can robot, the helium leak detector chamber, the swipe counter, and a transfer cart. The enclosure will be sealed and vented during normal operations, but it will have an automated door to allow filled cans to leave on the transfer cart and several manual doors for maintenance. The enclosure is sealed to prevent contamination spread in the event the bagless transfer sphincter seal fails. The enclosure will be vented to the facility hood exhaust system and HEPA filters will isolate the enclosure from the hood exhaust duct work. The enclosure will be approximately 72 inches long, 48 inches wide, and 60 inches high. The enclosure will be fabricated from 304 stainless steel.

\section{Can Welder}

The can welder will weld the can plug to the can wall from outside the can. The FB-Line bagless transfer system uses a commercially available TIG welder by Arc Machines Inc., as will the can loading bagless transfer welder. The welder will be sized to fit around a 3 inch outer diameter can and the welding head must be compatible with the 0.040 inch thick $304 \mathrm{~L}$ stainless steel can wall and 0.125 inch thick $304 \mathrm{~L}$ stainless steel hollow plug.

\section{Can Cutter}

The can cutter will cut the puck can and hollow plug in the weld area to separate the can of pucks from the stub. The FB-Line bagless transfer system uses a commercially available Tri-Tool Inc. pipe cutter, as will the can loading bagless transfer cutter. The cutter will be sized to clamp 
around the 3 inch outer diameter cans and cut through the 0.040 inch thick can wall and the 0.125 inch thick hollow plug wall. The can and plug will be fabricated from 304L stainless steel.

\section{Can Holder}

The can holder will support, raise, and lower the puck cans while they are in the bagless transfer system. The can holder will also hold and rotate the can while the can robot swipes the can for contamination. The can holder maximum payload will be a filled 25 pound puck can plus the force required to push the can through the sphincter seal. The can holder will be shaped like a cup and sized to hold a 3 inch outer diameter can. The holder will have enough clearance to allow the can robot to remove the cans from the can holder. The can holder parts will be fabricated from 304 stainless steel where ever possible.

\section{Can Robot}

The can robot will load and unload puck cans in the bagless transfer system, maneuver swipes over the puck cans, load and unload swipes in the swipe counter, load and unload cans in the decontamination chamber, load and unload cans in the leak detector, and place puck cans on the transfer cart. The can robot maximum payload will be the 25 pound fully loaded puck can. The can robot requires 6 rotational degrees of freedom (DOF) and a gripper. The six DOFs allows the robot to maneuver the swipe over the cylindrical can surface and to load and unload puck cans at various stations. The can robot will need a minimum radial reach of 30 inches. This will allow the robot to reach all the stations inside the bagless transfer enclosure. A preliminary market search revealed that commercially available 6 DOF robots with a 25 pound payload have a radial reach greater than 5 feet. The can robot must perform the required tasks within the 72 inches long, 48 inches wide, and 60 inch tall bagless transfer enclosure. The can robot requires a repeatability of $+/-0.020$ inches and each DOF requires a velocity range from 0 to 40 degrees/second.

The gripper will hold 3 inch diameter puck cans and can swipes. Since swipes are typically very thin and hard for a gripper to handle, a swipe holder will be used. The can robot and gripper parts will be fabricated from 304 stainless steel where ever possible and all moving parts will be covered when possible. If possible, the internal cavities will be slightly pressurized to help prevent contamination from entering the robot and gripper.

\section{Helium Leak Detector Chamber}

The helium leak detector chamber will perform leak checks on the puck cans after they are welded by the bagless transfer system. The chamber will be sized to hold the 3 inch outer diameter by 20 inch long (nominally) puck can. The chamber will be opened and closed by the can robot or dedicated actuators. The chamber will open so that the can robot can easily load and unload puck cans in the chamber. The chamber must seal well enough to perform hundreds of helium leak checks before the seal system fails. The chamber and associated pump system will pull a vacuum sufficient for the helium detector. The helium leak detector chamber parts will be fabricated from 304 stainless steel where ever possible and all moving parts will be covered when possible. 


\section{Helium Detector}

The helium detector will analyze the gasses from the helium leak detector chamber. If helium is detected above a specified leak rate, the can will fail the leak/weld inspection. The detector will be a commercially available mass spectrometer calibrated for helium. The detector will be located outside the bagless transfer enclosure.

\section{Swipe Counter}

The swipe counter will perform radiation counts on the puck can swipe pads. The swipe counter will be a commercially available unit sized to count swipes that the can robot can easily handle. The swipe counter will be opened and closed by the can robot or dedicated actuators. The swipe counter will require adequate shielding to perform radiation counts within a few feet of pucks. The swipe counter parts will be fabricated from 304 stainless steel where ever possible.

\section{Can Decontamination Chamber}

The can decontamination chamber will remove contamination from puck cans that fail the smear test. The chamber will be sized to hold the 3 inch outer diameter by 20 inch long (nominally) puck can. The chamber will be opened and closed by the can robot or dedicated actuators. The can robot must be able to easily load and unload puck cans in the chamber. The chamber must seal well enough to perform hundreds of cleanings before the seal system fails. The can decontamination chamber parts will be fabricated from 304 stainless steel where ever possible and all moving parts will be covered when possible. The cleaning method, such as $\mathrm{CO}_{2}$ snow, will be compatible with the 304 stainless steel puck cans and chamber. Waste from the decontamination chamber are not addressed in this report.

\section{Magnetically Coupled Transport Cart}

The magnetic coupled transport cart will remove full puck cans and used swipes from the bagless transfer enclosure and bring empty cans and new swipes to the enclosure. The cans and swipes will be placed in a special rack and the transfer cart will move this rack. The rack will hold 3 cans in the vertical position and a cartridge of swipes. A full puck can weighs about 25 pounds, the rack will weigh approximately 20 pounds, and the swipe cartridge will weigh about 5 pounds, so the transport cart must be able to handle a 100 pound payload. The rack and transport cart parts will be fabricated from 304 stainless steel where ever possible. The magnetically coupled cart design will allow the drive system and other components to be installed outside the enclosure for easy maintenance and cleaning. The cart and cart rails will be the only system parts inside the enclosure.

\section{Control System}

The can loading control system will interface on a high level with other facility computer systems such as; the Material Control \& Accountability system and the inter-glovebox transport system. The control system will interface on a high level with the can loading puck robot controller and the can robot controller. The control system will interface on a low level with the tray elevator, transfer carts, airlock doors, lift stations, etc. A high level computer interface is the exchange of complex or multi-step commands like; send more pucks or load a new can. A low level computer 
interface is the exchange of simple or single step commands like; run the cart motor clockwise or stop the cart motor. The can loading control system will allow single point of control for the entire system.

\section{CAN LOADING ISSUES}

The following paragraphs describe four can loading issues and recommends a solution for each. The can loading conceptual design incorporates these recommendations.

\section{Tray Staging vs Puck Staging}

This issue deals with how to stage pucks in the can loading glovebox while the puck robot is loading them into the puck can. The first option is tray staging. The tray staging system provides equipment to hold two trays in the glovebox. The puck robot can access pucks on either tray and the cart can move one tray under a second tray at a lift station The advantages to staging the trays of pucks are; each puck is handled once in the glovebox and the entire puck inventory can be removed from the glovebox in a short time if personnel need glovebox access. The disadvantage to tray staging is that parts of the lift stations are inside the glovebox.

The second option is puck staging. The puck staging method would move pucks from the tray to the glovebox floor as soon as the tray enters the glovebox. The advantage to staging the pucks on the glovebox floor is that no staging equipment (lift stations) is required in the glovebox. The disadvantage is that each puck is handled twice.

This report recommends staging pucks on trays in the can loading glovebox for the following reasons; 1 ) the ability to remove pucks from the glovebox if the robot needs manual maintenance is good ALARA practice, 2) the ability to stage two trays in the glovebox allows more flexibility for the inter-glovebox transport system, 3) placing pucks on the glovebox floor will cause material to gather on the floor and require more cleaning, and 4) each puck must be handled twice.

\section{Helium Hood vs Helium Atmosphere}

This issue deals with how to get a sufficient amount of helium into the puck can for the weld inspection. Per DOE 3013 and ANSI N14.5-1987, standards for the storage and shipping of radioactive materials, sealed containers must provide a leak rate below $1 \times 10^{-7} \mathrm{std}$. cc/min of air. This correlates to $1.96 \times 10^{-7} \mathrm{std}$. $\mathrm{cc} / \mathrm{min}$ of helium. This stipulation requires the introduction of a leak detection gas. With the container filled with the leak detection gas, it can then be checked for leaks. A leak rate less than the stipulated requirement will pass this test.

Helium is the predominant leak detection gas, but other gases can be used, including argon, nitrogen, ${ }^{85} \mathrm{Kr}$, and halogens. The use of helium has become widespread because of several factors, including small molecular weight (and hence size of molecule), the non-reactivity of helium, and the non-toxic characteristics of helium. Of the gases available, helium, nitrogen, and argon have been used in gloveboxes in the DOE complex. These gases require their own recycling system, and typically use approximately 4300 liters/day of gas. The gas of choice would be helium for its ability to propagate through the smallest cracks and the availability of helium detection equipment commercially. 
The first option is the helium hood. The helium hood concept is a small device that fits over the puck can top and seals to the can. The hood pulls a vacuum on the can interior, introduces helium, and inserts the can plug. The hood is similar to the one currently in use by the SRS FBLine bagless transfer system. The advantages to the helium hood are; the method is proven in radioactive service, it guarantees high percentage of helium in the can, and it requires a minimal amount of helium.

The second option is a helium atmosphere in the can loading glovebox. The helium atmosphere method fills the entire can loading glovebox with helium to get helium into the puck can. The advantage to the helium atmosphere is it doesn't require additional equipment in the glovebox. The following are disadvantages to the helium atmosphere. 1) The method requires a significant amount of helium to maintain the atmosphere. Initial calculations show it will take one liter of helium per minute to maintain the helium atmosphere in one glovebox and two additional liters of helium each time a new can is exposed to a glovebox. This totals 4300 plus liters of helium per day for 3 can loading gloveboxes and only provides $50 \%$ of helium in the puck cans. 2) Helium, being lighter than air, will tend to rise quickly from the can so there is no guarantee what helium percent will be in the can. 3) The need for a gas lock between the glovebox and the elevator.

This report recommends using the helium hood to introduce helium into the puck cans for the following reasons; 1) the method is proven in radioactive service by the SRS FB-Line bagless transfer system, 2) the helium atmosphere method requires a significant amount of helium to maintain the atmosphere, and 3) the helium atmosphere will not guarantee a high percentage of helium in the puck can.

\section{Can Robot vs Hard Automation}

This issue deals with the method for handling the full puck cans in the bagless transfer enclosure. The full puck cans must be swiped, the swipe pads loaded and unloaded in a radiation counter, the cans loaded and unloaded in a helium leak chamber, the cans loaded and unloaded in a decontamination chamber, and the cans placed on a transport cart. The first option is using a single can robot. The can robot method uses a single 6 axis robot to perform all the can tasks, except the bagless transfer can holder could rotate the can during swiping. The advantages to using the robot are; there is only one piece of moving equipment and the robot will be reliable.

The second option is hard automation. The hard automation method uses individual actuators, conveyors, motors, etc. to perform the can tasks. The advantages to using hard automation are; all components are light weight and inexpensive.

This report recommends using the can robot to perform the can handling tasks for the following reasons; 1) preliminary hard automation concepts require fifteen automated motions and this presents a very complicated system to maintain due to the extensive equipment, and 2) the system will be custom made and thus require significant development costs.

\section{Can Swiping}

This issue deals with defining the areas that require swiping after the bagless transfer system cuts and lowers the puck can. The concept being considered is to swipe the exposed can surface while it is in the bagless transfer can holder. This includes the can top, weld area, and the top $3 / 4$ of the 
can exterior. The can weld area and the sphincter seal are the most likely paths for contamination to enter the enclosure. Contamination entering from the weld area or sphincter seal will probably be on the can top, in the weld area, or fall down the can side and land in or on the can holder. The concept being considered swipes the can top, weld area, and can side. This report recommends that the entire can holder also be swiped. This must be done after the can robot removes the can from the can holder to allow access to the can holder.

\section{DEVELOPMENT AREAS}

The following issues require further development to ensure a successful Pu Immobilization can loading system.

High Priority

1. Load pucks in cans

2. Fill can with helium and insert plug

3. Tray staging system

4. Handling pucks from reject cans

5. Handle full cans (load bagless transfer, leak detector, etc.)
Low Priority

1. Modify current bagless transfer design

2. Can swiping

3. Helium bell jar for leak detection

4. Cut open reject cans

5. Handle waste (stubs, reject cans)

\section{CONCLUSIONS}

This report discusses the Plutonium Immobilization can loading conceptual design. The process block diagram, see attachment 1, details the required can loading steps and is based on the Plutonium Immobilization Plant, First Stage Immobilization, Process Flow Drawing. The process description discusses the steps required to process pucks and the steps to handle some process failures. The can loading equipment section describes the preliminary equipment concepts for each piece of equipment in the can loading conceptual design. Attachments 2 through 4 show the can loading conceptual design plan and elevation views. This report recommends that trays of pucks be staged in the can loading glovebox, a 3 degree of freedom Cartesian robot loads the pucks into puck cans, a helium hood be used to introduce helium into the puck cans and insert the hollow plug into the can, a six axis robot be used to handle the full puck cans, and that the swiping operations include the bagless transfer can holder. The equipment items in the can loading conceptual design must be tested, integrated, and demonstrated to ensure a successful Plutonium Immobilization can loading system. 


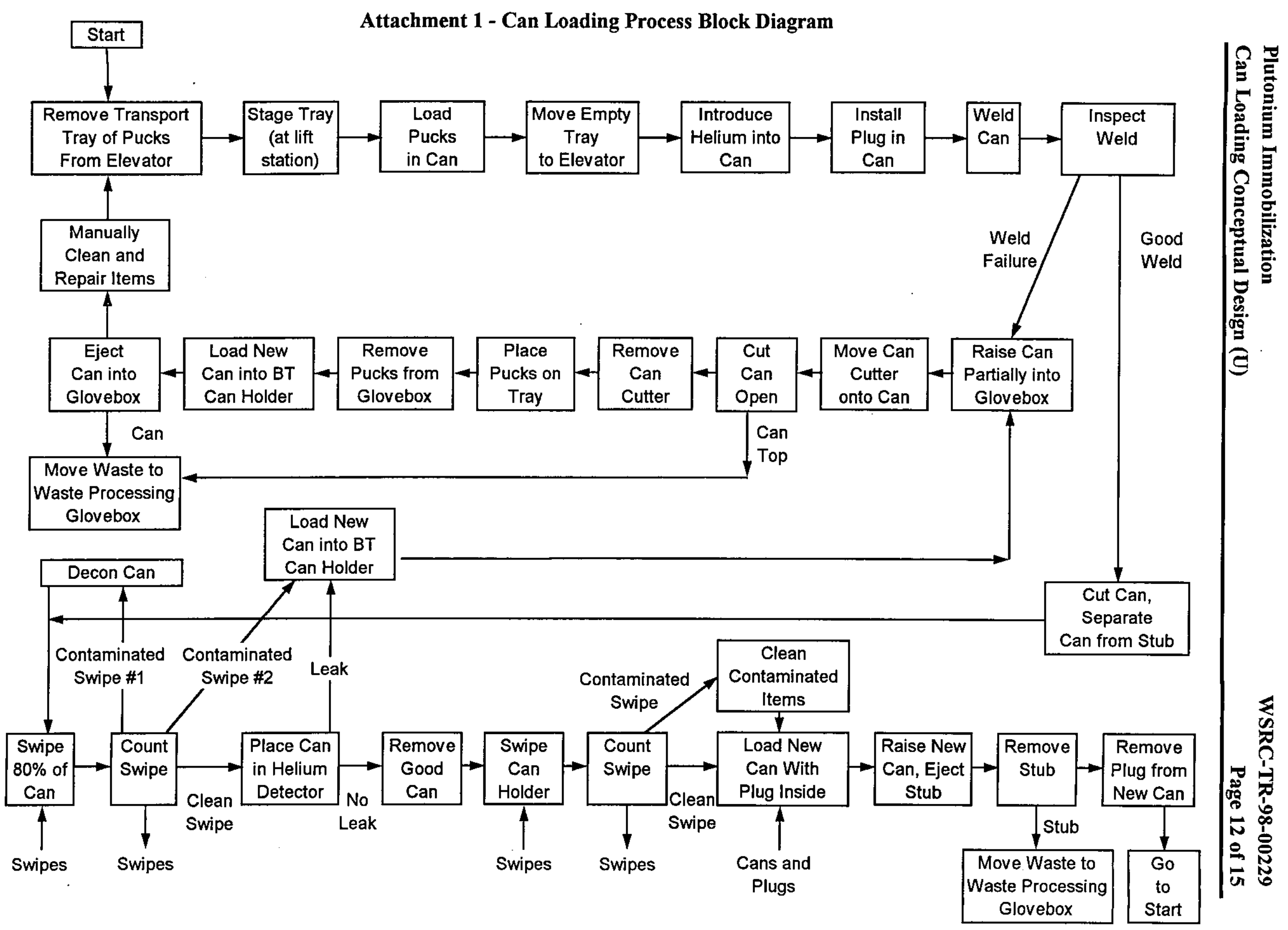




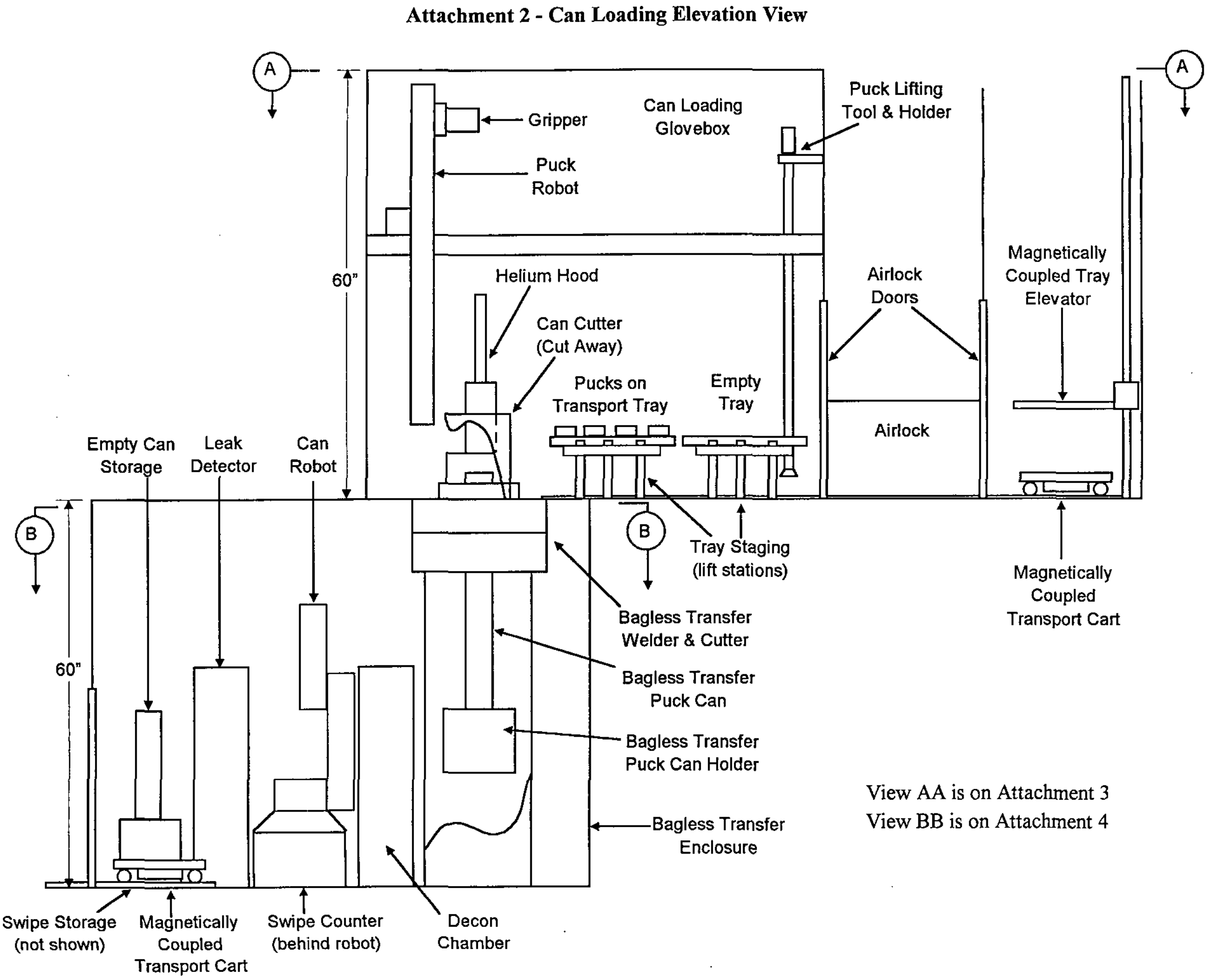




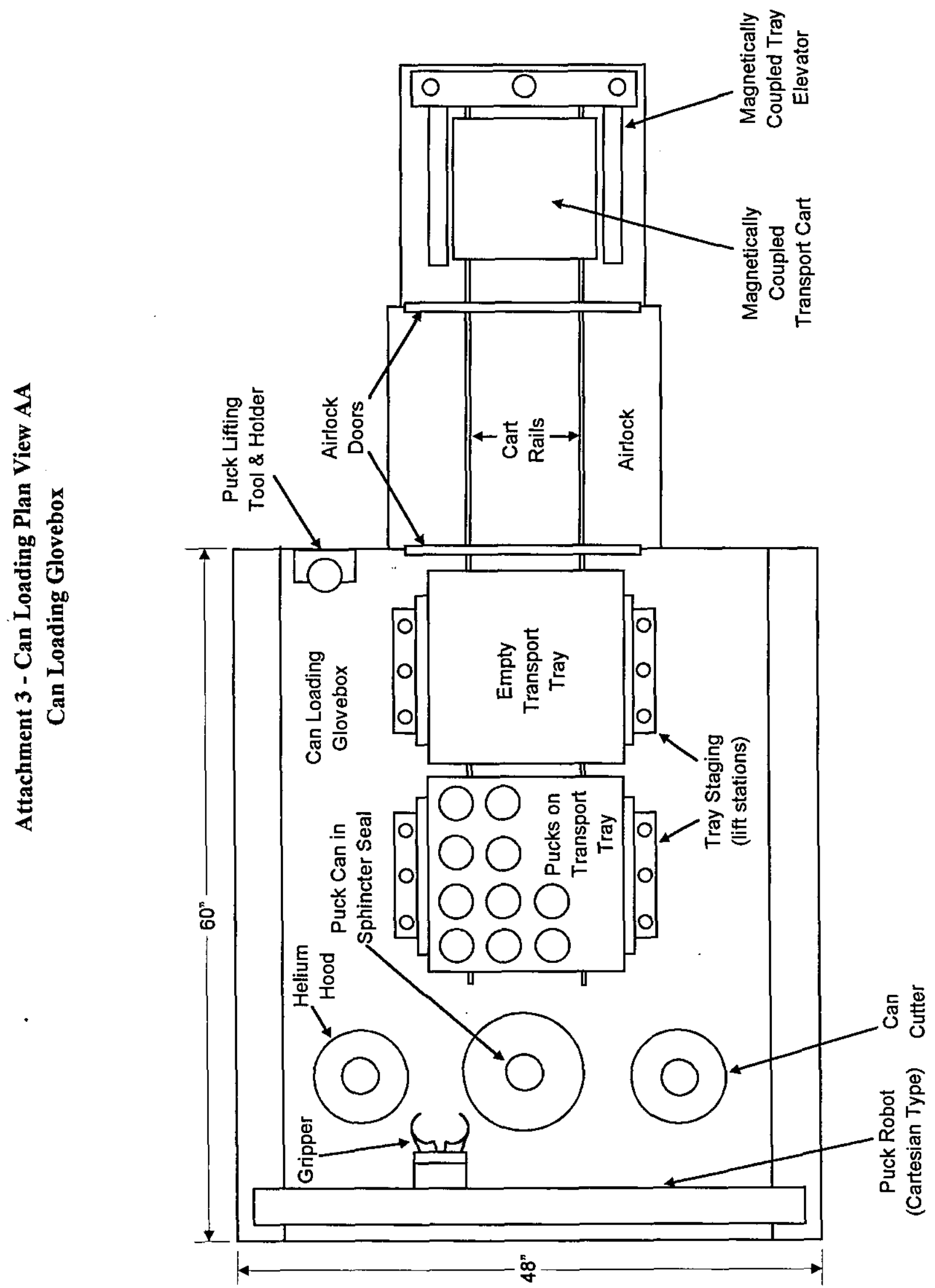


Attachment 4 - Can Loading Plan View BB

Bagless Transfer Enclosure
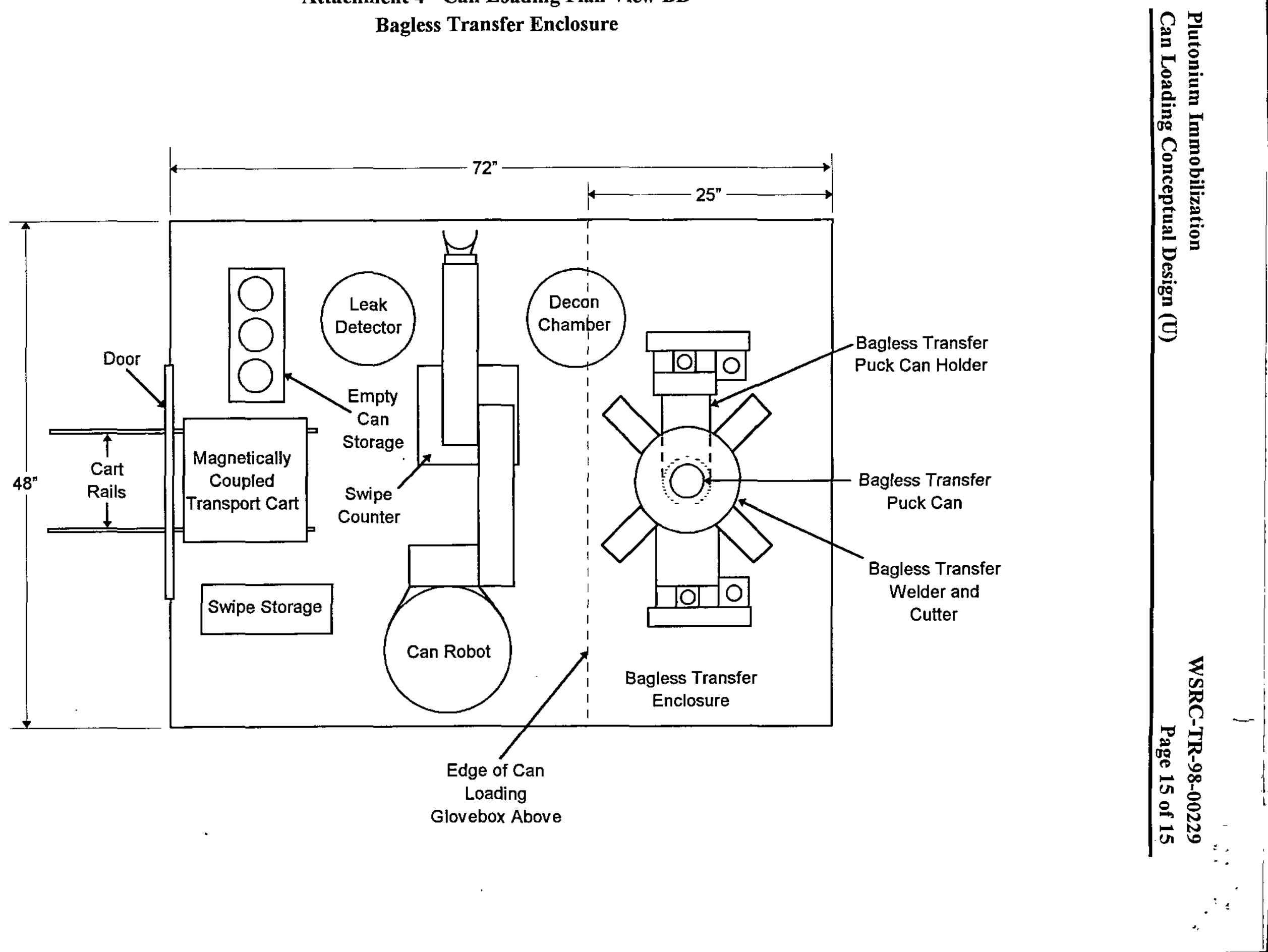